BMJ Open

Diabetes

Research

\& Care

\section{Statin use and risk of developing diabetes: results from the Diabetes Prevention Program}

To cite: Crandall JP, Mather K Rajpathak SN, et al. Statin use and risk of developing diabetes: results from the Diabetes Prevention Program. BMJ Open Diab Res Care 2017;5:e000438. doi:10.1136/ bmjdrc-2017-000438

- Additional material is published online only. To view please visit the journal online (http://dx.doi.org/10.1136/ bmjdrc-2017-000438).

Received 16 May 2017 Revised 22 August 2017 Accepted 29 August 2017

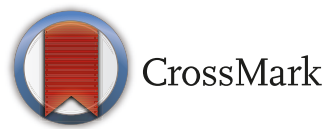

For numbered affiliations see end of article.

Correspondence to Dr Jill P Crandall; jill.crandall@einstein.yu.edu

\section{ABSTRACT}

Objective Several clinical trials of cardiovascular disease prevention with statins have reported increased risk of type 2 diabetes (T2DM) with statin therapy. However, participants in these studies were at relatively low risk for diabetes. Further, diabetes was often based on selfreport and was not the primary outcome. It is unknown whether statins similarly modify diabetes risk in higher risk populations.

Research design and methods During the Diabetes Prevention Program Outcomes Study $(n=3234)$, the long-term follow-up to a randomized clinical trial of interventions to prevent T2DM, incident diabetes was assessed by annual $75 \mathrm{~g}$ oral glucose tolerance testing and semiannual fasting glucose. Lipid profile was measured annually, with statin treatment determined by a participant's own physician outside of the protocol. Statin use was assessed at baseline and semiannual visits. Results At 10 years, the cumulative incidence of statin initiation prior to diabetes diagnosis was $33 \%-37 \%$ among the randomized treatment groups ( $p=0.36)$. Statin use was associated with greater diabetes risk irrespective of treatment group, with pooled $\mathrm{HR}(95 \% \mathrm{Cl})$ for incident diabetes of 1.36 (1.17 to 1.58). This risk was not materially altered by adjustment for baseline diabetes risk factors and potential confounders related to indications for statin therapy.

Conclusions In this population at high risk for diabetes, we observed significantly higher rates of diabetes with statin therapy in all three treatment groups. Confounding by indication for statin use does not appear to explain this relationship. The effect of statins to increase diabetes risk appears to extend to populations at high risk for diabetes. Trial registration number NCT00038727; Results.

\section{INTRODUCTION}

The health benefits of the 3-hydroxy-3-methylglutaryl (HMG)-coenzyme A reductase inhibitors ('statin' medications) are thought to extend beyond their cholesterol-lowering properties. Such pleiotropic actions of statins may include favorable effects on systemic inflammation, endothelial function and oxidative stress, ${ }^{1}$ important mechanisms involved in the etiology of cardiometabolic

\section{Significance of this study}

What is already known about this subject?

- In observational studies, statin use has been associated with increased risk for diabetes.

- Data from randomized statin trials also suggest incident diabetes is increased.

What are the new findings?

- In a population at high risk for diabetes in which incident diabetes was rigorously detected, statin use remains a diabetes risk factor.

- Incident diabetes among statin users was accompanied by a decline in insulin secretion.

How might these results change the focus of research or clinical practice?

- Patients at high risk for diabetes should be monitored during statin therapy.

- Additional studies are needed to explore the mechanisms for statin-associated diabetes.

diseases. These effects might be predicted to reduce diabetes risk; instead, accumulating evidence suggests that the use of statins may increase the risk of developing type 2 diabetes. Following an initial publication reporting this observation, ${ }^{2}$ meta-analyses of randomized clinical trials of lipid-lowering with statins have confirmed this effect, and suggest that statin treatment is associated with a small increase, approximately $10 \%-12 \%$, in the risk of incident diabetes compared with placebo, ${ }^{3-6}$ although not all such analyses find increases in diabetes risk. ${ }^{7}$

In these cardiovascular disease (CVD) prevention trials, diabetes was not the primary outcome, diabetes ascertainment was not always based on laboratory testing, and the absolute risk of developing diabetes was relatively low in the study populations. These factors may have limited the sensitivity of the evaluations for observing effects 
of statins on diabetes incidence. Diabetogenic effects of statins may be more important among individuals with higher risk of diabetes. In a post-hoc analysis of two of the studies contributing to the meta-analyses, the elevated risk appeared to be focused on the subset of study participants who had pre-diabetes based on elevated glucose readings. ${ }^{8}$ We therefore conducted an analysis to evaluate the statin-diabetes association using data from the Diabetes Prevention Program (DPP), which studied a cohort of overweight and obese individuals at high risk for diabetes, followed specifically for incident diabetes.

\section{METHODS}

The DPP was a randomized clinical trial testing interventions to prevent or delay the development of diabetes mellitus (DM) among high-risk individuals. ${ }^{9}$ The 27 clinical centers in the USA recruited 3234 participants of both sexes, approximately $50 \%$ of whom were members of ethnic or racial minority groups and $20 \%$ of whom were $\geq 60$ years old. The eligibility criteria included $\geq 25$ years of age, body mass index (BMI) $\geq 24 \mathrm{~kg} / \mathrm{m}^{2}$ ( $\geq 22 \mathrm{~kg} / \mathrm{m}^{2}$ in Asian-Americans), and both fasting plasma glucose levels of between 95 and $125 \mathrm{mg} /$ $\mathrm{dL}$ and impaired glucose tolerance (IGT) (2-hour $75 \mathrm{~g}$ postload glucose of $140-199 \mathrm{mg} / \mathrm{dL}$ ). Major exclusions included a recent myocardial infarction, symptoms of coronary heart disease, major illness, prior diagnosis of $\mathrm{DM}$, or treatment with glucose-lowering medications, use of medications known to impair glucose tolerance and a triglyceride level $\geq 600 \mathrm{mg} / \mathrm{dL}$. Eligible participants received standard advice on healthy diet and physical activity, and were randomly assigned to an intensive lifestyle intervention, metformin or placebo. At the end of the main trial (mean follow-up 3.2 years), all participants were offered a group-administered version of the lifestyle intervention and were invited to enroll in the DPP Outcomes Study (DPPOS).$^{10}$ During the DPPOS, all participants were offered quarterly lifestyle sessions, the former metformin group received open-label metformin and the former intensive lifestyle group was offered two additional lifestyle program per year. This report includes data up to August 31, 2008, with the median follow-up from randomization to the most recent evaluation being 10.0 years. The protocol was approved by each center's institutional review board and all participants provided written informed consent.

Lipid profiles and blood pressure were measured annually during DPP and DPPOS, and reports were provided to the participants, including information as to whether lipid levels had reached recommended treatment targets as defined by Adult Treatment Panel (ATP) III. Prescriptions for lipid-lowering and antihypertensive medications were managed by the participant's own medical provider, outside of the study protocol.

\section{Assessment of statin use}

In the DPP and DPPOS, statins use was recorded along with other concomitant medications based on self-report. This information was collected at baseline and at each semiannual follow-up visit, based on the question 'Has the participant taken any prescription medications within the past 2 weeks?' Participants were asked to bring all prescription pill bottles to each visit and drug name was recorded. Cumulative statin use was defined as the number of semiannual visits with reported use.

\section{Diagnosis of diabetes}

Diabetes diagnosis was the primary endpoint for DPP/ DPPOS. This was determined by an annual $75 \mathrm{~g}$ oral glucose tolerance test or by a semiannual fasting plasma glucose level with confirmation by a second test, using the standardized criteria of the American Diabetes Association $^{11}$ and the WHO. ${ }^{12}$

\section{Assessment of covariate data}

Body weight was measured to the nearest $0.1 \mathrm{~kg}$ semiannually. Waist circumference was measured annually in the standing position, midway between the highest point of the iliac crest and the lowest point of the costal margin in the midaxillary line. Semiannual blood pressure measurements were conducted using calibrated anaeroid or mercury sphygmomanometers by certified clinic staff, calculated as the average of two readings in seated participants. ${ }^{13}$ Data on age, family history of diabetes and race/ethnicity were based on self-reports. Fasting plasma glucose, insulin, glycated hemoglobin (HbAlc) and lipid profiles were measured in the Central Biochemical Laboratory (University of Washington, Seattle, Washington, USA) ${ }^{14}$ The Insulinogenic Index $\left(\mathrm{I}_{30}-\mathrm{I}_{0} / \mathrm{Glu}_{30}-\right.$ $\mathrm{Glu}_{0}$ ) was used to assess insulin secretion. ${ }^{15}$

\section{Statistical analyses}

Between-group comparisons were performed using the $\chi^{2}$ test of independence for qualitative variables and using analysis of variance or t-tests for quantitative variables. Triglycerides, which have a highly skewed distribution, were evaluated using the non-parametric KruskalWallis or Wilcoxon tests. For analyses of changes over time in quantitative measures, we used the normal errors longitudinal regression model. ${ }^{16}$ Interaction between treatment groups and time was assessed to determine if changes over time varied across treatment groups. Analysis of change from DPP randomization until the analysis closing date was adjusted for the DPP baseline value. The time to statin initiation was censored at the time of diabetes diagnosis or at the last visit for those who did not develop diabetes, and assessed with the use of life-table methods. Modified product-limit curves for the cumulative incidence of diabetes were compared with the use of the log-rank test.

Univariate and multivariate Cox proportional hazards models were used to assess the time-dependent association between statin use and diabetes onset risk. The Wald 


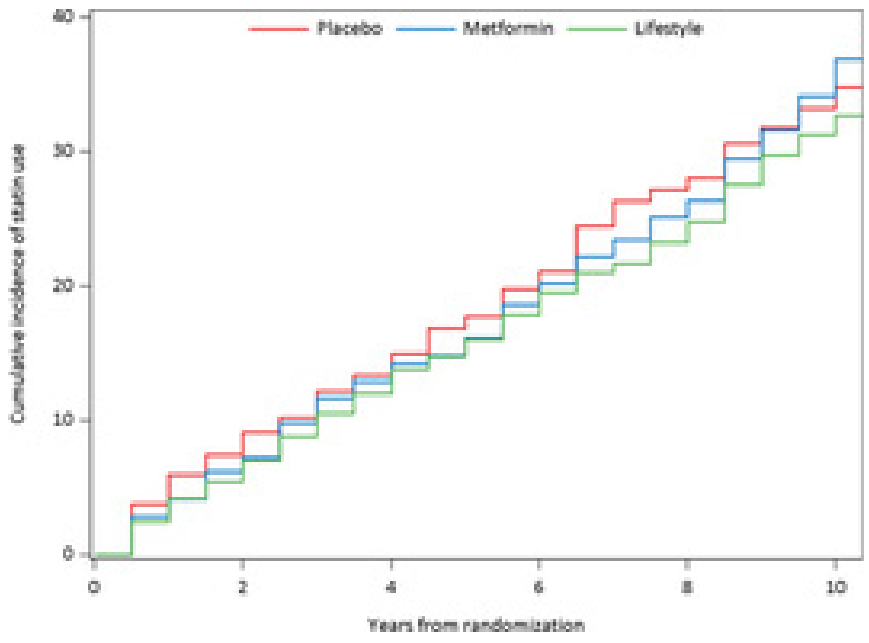

Figure 1 Cumulative incidence of statin initiation by treatment group.

test provided $p$ values and $R^{2}$ values for individual covariates, and the likelihood ratio test was used to evaluate contributions of covariates in the combined model. To facilitate comparisons of contributions across variables, HRs were reported for convenient increments approximating $1 \mathrm{SD}$ of continuous measure. Models were run separately for each treatment group, and a test of heterogeneity was used to evaluate whether an effect differed across treatment groups. Metabolic variables in the time-dependent proportional hazards analyses were entered as values from the visit immediately preceding diabetes evaluation.

All statistical analyses were performed using SAS V.9.4 software. All statistical tests conducted were two-sided and $\mathrm{p}$ values less than 0.05 were considered statistically significant, without adjustment for multiple testing.

\section{RESULTS}

Statin use was infrequent at DPP baseline ( 4\%), but increased progressively over the duration of the study. At 10 years of follow-up, the cumulative incidence of reported statin use prior to diabetes diagnoses was similar among the treatment groups, with $35 \%, 37 \%$ and $33 \%$ in the placebo, metformin and lifestyle groups, respectively $(\mathrm{p}=0.36)$ (figure 1). The most commonly used statins were simvastatin and atorvastatin $(40 \%$ and $37 \%$, respectively), followed by lovastatin (9\%) and pravastatin (8\%). The prevalence of statin use increased over time and was substantially higher following the diagnosis of diabetes (online supplementary figure A).

Baseline characteristics of the full study cohort $(\mathrm{n}=3234)$ according to statin use (at any time during DPP or DPPOS) are shown in table 1. Participants who used statins were older and more likely to be male, but did not differ by race/ethnicity. Statin users had modestly higher baseline fasting plasma glucose (FPG) and HbAlc, and lower Insulinogenic Index, than non-statin users, biasing these participants toward higher risk for diabetes. Baseline levels of LDL-cholesterol and triglycerides were higher in participants who took statins compared with those not on statins. A history of CVD and hypertension was also more frequent among statin users. Socioeconomic status (defined by years of education and income level) did not differ by reported statin use (data not shown). None of these variables differed by treatment group assignment.

The HRs for the development of diabetes associated with prior statin use are shown in table 2 (and online supplementary figure B). We used sequential models that controlled for demographics (age, sex and race/ethnicity; model 1); demographics plus baseline diabetes risk factors (fasting glucose, Insulinogenic Index, 1/fasting insulin and waist circumference; model 2); and models for further adjustment for potential confounders related to indication for statin use (HDL-C, LDL-C, DBP, SBP, history of CVD, SES and antihypertensive use at the visit prior to diabetes assessment; model 3). Intervention-related changes in diabetes risk factor levels (1/fasting insulin, Insulinogenic Index, waist circumference) were added in model 4, and model 5 represents concurrent adjustments of model 2 for indications for statin use and changes in diabetes risk factors. In the placebo group, the HRs (95\% CIs) for diabetes were 1.21 (0.93 to 1.57 ) (model 1, demographics), 1.18 (0.90 to 1.54) (model 2, baseline diabetes risk factors) and 1.15 (0.87 to 1.53) (model 3, indications for statin use). For the metformin group, the HR in model 1 was 1.33 (1.02 to 1.73), essentially unchanged following adjustment for diabetes risk factors (model 2), but lost statistical significance with a modestly lower HR after adjustment for indications for statin use in model 3 (HR 1.31 (0.99 to 1.73). Among lifestyle participants, the HR was 1.59 (1.21 to 2.10) in model 1, essentially unchanged in model 2 (HR 1.53 (1.16 to 2.03)), and (similar to the metformin group) was modestly attenuated and lost significance after adjustment for potential statin treatment confounders in model 3 (HR 1.36 (1.00 to 1.86)) and changes in diabetes risk factors (model 4). Concurrent adjustment for indications for statin use and updated diabetes risk factors (model 5) did not substantially alter the HR in any of the treatment groups. The test of heterogeneity comparing randomized treatments was not significant in each of the models, indicating these HRs were not statistically different across treatment groups. With all three treatment groups combined, the HR associated with statin use corresponding to model 1 was 1.36 (1.17 to 1.59$)$. We found no interaction between sex and statin use (or total statin exposure) on diabetes risk.

We also analyzed diabetes risk in relation to duration of statin exposure (figure 2), defined as number of semiannual visits with reported statin use. Baseline statin users $(\mathrm{n}=141)$ were excluded from this analysis since duration of use prior to study enrollment was not available. Longer duration of statin use was significantly associated with greater diabetes risk in the lifestyle group (HR per visit with statin use: 1.06 (1.02 to 1.11$), \mathrm{p}=0.007)$. In the 
Table 1 Baseline characteristics according to reported statin use at any time during DPP and DPPOS

\begin{tabular}{|c|c|c|c|c|c|c|}
\hline & \multicolumn{2}{|l|}{ Placebo } & \multicolumn{2}{|l|}{ Metformin } & \multicolumn{2}{|l|}{ Lifestyle } \\
\hline & $\begin{array}{l}\text { No reported } \\
\text { statin use } \\
(n=614)\end{array}$ & $\begin{array}{l}\text { Statin use } \\
\text { reported } \\
(n=468)\end{array}$ & $\begin{array}{l}\text { No reported } \\
\text { statin use } \\
(n=629)\end{array}$ & $\begin{array}{l}\text { Statin use } \\
\text { reported } \\
(n=444)\end{array}$ & $\begin{array}{l}\text { No reported } \\
\text { statin use } \\
(n=672)\end{array}$ & $\begin{array}{l}\text { Statin use } \\
\text { reported } \\
(n=407)\end{array}$ \\
\hline Age (years) & $48.4(10.6)$ & $52.8(9.6)^{*}$ & $49.2(10.5)$ & $53.3(9.5)^{*}$ & $48.8(11.7)$ & $53.6(9.9)^{*}$ \\
\hline \multirow[t]{2}{*}{ Sex } & $27 \%$ male & $36 \%$ male $^{*}$ & $31 \%$ male & $38 \% \mathrm{male}^{\star \star \star}$ & $30 \%$ male & $36 \%$ male $^{\star * *}$ \\
\hline & $73 \%$ female & $64 \%$ female & $69 \%$ female & $62 \%$ female & $70 \%$ female & $64 \%$ female \\
\hline \multirow[t]{5}{*}{ Race/ethnicity } & C 52\% & C $57 \%$ & C $54 \%$ & C 59\% & C $52 \%$ & C $57 \%$ \\
\hline & AA $22 \%$ & AA $19 \%$ & AA $20 \%$ & AA $21 \%$ & AA $19 \%$ & AA $18 \%$ \\
\hline & H 16\% & H 15\% & H 16\% & H $14 \%$ & H 18\% & H $14 \%$ \\
\hline & $\mathrm{Al} 4 \%$ & Al 6\% & Al 3\% & Al 3\% & Al 5\% & Al 6\% \\
\hline & A $6 \%$ & A $4 \%$ & A $6 \%$ & A $3 \%$ & A $6 \%$ & A $5 \%$ \\
\hline $\begin{array}{l}\text { Body mass index } \\
\left(\mathrm{kg} / \mathrm{m}^{2}\right)\end{array}$ & $34.5(7)$ & $33.7(6)$ & $34.2(7)$ & $33.4(6)$ & $34.2(7)$ & $33.4(6)$ \\
\hline Waist (cm) & 105 (15) & $105(14)$ & $105(15)$ & 105 (13) & $105(15)$ & 105 (14) \\
\hline FPG (mg/dL) & $106(7)$ & $108(9)^{*}$ & $106(9)$ & $108(9)^{*}$ & $105(7)$ & $108(9)^{*}$ \\
\hline $\begin{array}{l}\text { Two-hour glucose } \\
\text { (mg/dL) }\end{array}$ & 164 (18) & $166(16)$ & $164(16)$ & $166(18)$ & $164(16)$ & $166(18)$ \\
\hline $\begin{array}{l}\text { Insulinogenic } \\
\text { Index }\end{array}$ & $109(70,164)$ & $101(64,160)$ & $108(70,164)$ & $95(63,140)^{\star}$ & $109(68,170)$ & $95(65,140)^{*}$ \\
\hline $\begin{array}{l}\text { Fasting insulin } \\
(\mu \mathrm{lU} / \mathrm{mL})\end{array}$ & $24(17,33)$ & $25(16,33)$ & $24(16,35)$ & $23(17,33)$ & $23(16,34)$ & $24(16,33)$ \\
\hline HbA1c (\%) & $5.9(0.5)$ & $6.0(0.5)^{\star}$ & $5.9(0.5)$ & $6.0(0.5)^{\star}$ & $5.9(0.5)$ & $6.0(0.5)^{\star}$ \\
\hline $\begin{array}{l}\text { LDL-cholesterol } \\
(\mathrm{mg} / \mathrm{dL})\end{array}$ & $116(31)$ & $139(35)^{\star}$ & $116(27)$ & $139(35)^{\star}$ & $116(31)$ & $139(35)^{*}$ \\
\hline $\begin{array}{l}\text { HDL-cholesterol } \\
\text { (mg/dL) }\end{array}$ & $46(12)$ & 43 (12) & $46(12)$ & $46(12)$ & $46(12)$ & $46(12)$ \\
\hline $\begin{array}{l}\text { Triglycerides (mg/ } \\
\mathrm{dL} \text { ) }\end{array}$ & $142(97,186)$ & $160(115,230)^{*}$ & $124(89,178)$ & $160(115,221)^{*}$ & $124(88,186)$ & $160(115,221)^{*}$ \\
\hline $\begin{array}{l}\text { Per cent with } \\
\text { hypertension }\end{array}$ & $23 \%$ & $34 \% *$ & $24 \%$ & $36 \% *$ & $25 \%$ & $35 \% *$ \\
\hline $\begin{array}{l}\text { Per cent with } \\
\text { history of CVD }\end{array}$ & $0.8 \%$ & $3.6 \%$ * & $0.5 \%$ & $2.5 \%$ * & $0.9 \%$ & $1.7 \%$ \\
\hline $\begin{array}{l}\text { Per cent with } \\
\text { family history of } \\
\text { diabetes }\end{array}$ & $72 \%$ & $68 \%$ & $65 \%$ & $73 \% *$ & $70 \%$ & $69 \%$ \\
\hline
\end{tabular}

Data are expressed as mean (SD), median (IQR) or per cent as appropriate. Within each treatment group, significant comparisons between participants who reported statin therapy versus not are noted in bold with asterisk $\left(^{*}\right)$ for $p<0.001$, $\left({ }^{\star \star}\right)$ for $p<0.01$ and $\left(^{\star \star \star}\right)$ for $p<0.05$. Hypertension defined as blood pressure $>130 / 80 \mathrm{~mm} \mathrm{Hg}$ or use of antihypertensive medication.

A, Asian-American; AA, African-American; Al, American-Indian; C, Caucasian; CVA, cerebrovascular accident; CVD, cardiovascular disease: DPP, Diabetes Prevention Program; DPPOS, DPP Outcomes Study; FPG, fasting plasma glucose; H, Hispanic; HbA1c, glycated hemoglobin; HDL, high density liproprotein; LDL, low density lipoprotein; MI, myocardial infarction.

metformin and placebo group, the HRs per visit reported with statin use were 1.01 (0.96 to 1.06) and for placebo 1.02 (0.97 to 1.07$)$, respectively. Although neither of these reached statistical significance, the relationship of duration of exposure with diabetes risk was not statistically different between groups ( $p=0.26$ testing heterogeneity of these relationships across treatment groups).

To assess whether statin potency was related to diabetes risk, we grouped reported statin use into 'low potency' (pravastatin, lovastatin, fluvastatin, 19\%) or 'high potency' (atorvastatin, simvastatin, rosuvastatin, cerivastatin, 81\%) categories. Diabetes risk did not differ by low versus high potency statins, with HR of 0.96 (0.68 to 1.35 ), using the same adjustments in model 5 . Information about statin dose was not available, but statin dose and/or potency may be reflected in the magnitude of LDL reduction. We therefore assessed diabetes HR according to change in LDL-cholesterol, but found no association (data not shown). There was no apparent effect of statin potency to modify the effect of statin use on diabetes incidence. 
Table 2 HR $(95 \% \mathrm{Cl})$ for diabetes associated with statin use at visit prior to diabetes diagnosis

\begin{tabular}{|c|c|c|c|c|c|}
\hline Adjusted models & Pooled & Placebo & Metformin & Lifestyle & Group p value \\
\hline Model 1: demographic & 1.36 (1.17 to1.59) & 1.21 (0.93 to 1.57$)$ & 1.33 (1.02 to 1.73$)$ & 1.59 (1.21 to 2.10$)$ & 0.36 \\
\hline $\begin{array}{l}\text { Model 2: } \\
\text { 1+baseline diabetes risk } \\
\text { factors }\end{array}$ & 1.35 (1.15 to .57$)$ & $1.18(0.90$ to 1.54$)$ & $1.37(1.05$ to 1.78$)$ & 1.53 (1.16 to 2.03$)$ & 0.41 \\
\hline $\begin{array}{l}\text { Model 3: } \\
\text { 2+updated statin } \\
\text { confounders }\end{array}$ & 1.27 (1.08 to 1.50$)$ & $1.15(0.87$ to 1.53$)$ & 1.31 (0.99 to 1.73$)$ & 1.36 (1.00 to 1.86$)$ & 0.71 \\
\hline $\begin{array}{l}\text { Model } 4 \text { : } \\
\text { 2+updated diabetes risk } \\
\text { factors }\end{array}$ & 1.27 (1.08 to1.49) & $1.19(0.91$ to 1.55$)$ & $1.36(1.04$ to 1.76$)$ & 1.37 (1.04 to 1.81$)$ & 0.71 \\
\hline Model 5: fully adjusted & 1.27 (1.08 to 1.50$)$ & $1.20(0.90$ to 1.59$)$ & $1.33(1.01$ to 1.76$)$ & $1.43(1.06$ to 1.94$)$ & 0.70 \\
\hline
\end{tabular}

Adjusted HRs for updated statin use are noted in bold at significance level of $\alpha=0.05$ based on the following models: 1 : age, sex, and race/ ethnicity; 2: model 1+baseline diabetes risk factors (family history of diabetes, fasting plasma glucose, log Insulinogenic Index, log 1/ fasting insulin, waist); 3: model 2+time-dependent statin treatment confounders (use of antihypertensive medications, diastolic blood pressure, systolic blood pressure, HDL-cholesterol, and LDL-cholesterol), which were updated until visit prior to statin initiation or diabetes assessment, plus baseline SES (years of education and household income) and reported history of cardiovascular disease at baseline; 4: model 2+time-dependent diabetes risk factors (log 1/fasting insulin, log Insulinogenic Index, waist) updated until the visit prior to the assessment of diabetes; 5: model 3+updated diabetes risk factors. Group p value represents the test for heterogeneity of HR among treatment group.

HDL, high density lipoprotein; LDL, low density lipoprotein; SES, socioeconomic status.

We explored potential mechanisms by which statins may promote diabetes by analyzing mean change from baseline in insulin sensitivity (fasting insulin) and insulin

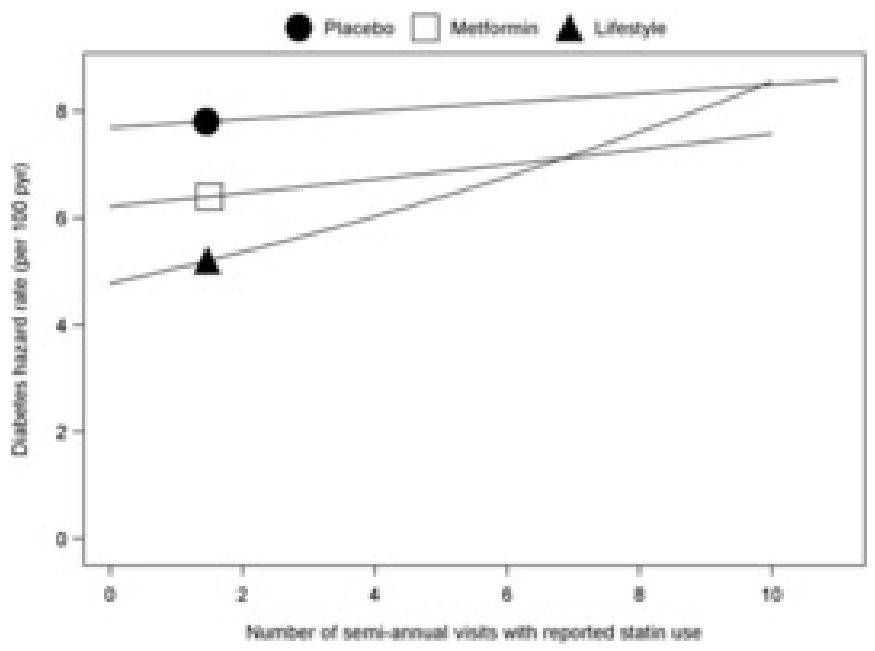

Figure 2 Diabetes hazard rates by number of visits with reported statin use. The risk of developing diabetes associated with the duration of exposure to statin therapy estimated using Cox proportional hazards models. The symbol on each line indicates the expected hazard rate for a subject with a number of visits with reported statin therapy equal to the mean value for the group over the group-specific range (5th-95th percentile). The risk for progression to diabetes by number of visits with reported statin use was calculated for each treatment group with model 5 from table 2 . The number of semiannual visits with reported statin use significantly predicted progression to diabetes only in the lifestyle group $(p=0.007)$; this relationship was not significantly different across the three groups (heterogeneity $\mathrm{p}=0.26$ ). secretion (Insulinogenic Index), according to statin use (table 3). In the active treatment groups, diabetes prevention was associated with favorable reductions in glucose and weight, and improvements in beta cell function. ${ }^{17} 18$ Statin use was associated with significantly smaller favorable changes in fasting glucose, 2-hour glucose, HbA1c and BMI. In the lifestyle group, Insulinogenic Index declined with statin use, compared with modest increase without statin use $(\mathrm{p}=0.013)$. There were no significant changes in fasting insulin in any of the groups, and no apparent pattern of change that would suggest an effect of statin use on insulin sensitivity. Overall, it appeared that the statin-treated participants were relatively resistant to the beneficial effects of DPP interventions on obesity and beta cell function.

\section{DISCUSSION}

This report is the first to evaluate the statin-diabetes association within a randomized clinical trial designed to carefully ascertain diabetes incidence in subjects at high risk for diabetes. In this analysis, statin use was associated with a clear increase in diabetes risk in the cohort as a whole, with point estimates of the HRs suggesting this risk is increased by close to $30 \%$. This augmented risk was only modestly attenuated with adjustment for variables related to the indication for statin treatment, suggesting that the indications for therapy were not themselves major contributors to diabetes risk. Participants who were prescribed statins had modestly higher levels of glucose at baseline, yet this also did not explain the higher rates of diabetes among statin users. Our data suggest the statin-associated diabetes risk did not differ significantly by treatment group, based on a test 
Table 3 Mean change from baseline of selected metabolic variables according to use of statins

\begin{tabular}{|c|c|c|c|c|c|c|c|c|c|}
\hline & \multicolumn{3}{|c|}{ Placebo } & \multicolumn{3}{|c|}{ Metformin } & \multicolumn{3}{|c|}{ Lifestyle } \\
\hline & $\begin{array}{l}\text { Statin } \\
\text { use }\end{array}$ & $\begin{array}{l}\text { No statin } \\
\text { use }\end{array}$ & p & $\begin{array}{l}\text { Statin } \\
\text { use }\end{array}$ & $\begin{array}{l}\text { No statin } \\
\text { use }\end{array}$ & p & $\begin{array}{l}\text { Statin } \\
\text { use }\end{array}$ & $\begin{array}{l}\text { No statin } \\
\text { use }\end{array}$ & $\mathbf{p}$ \\
\hline $\begin{array}{l}\text { Fasting glucose (mg/ } \\
\text { dL) }\end{array}$ & 3.0 & 1.9 & 0.04 & -0.3 & -1.3 & 0.03 & 0.8 & -0.4 & 0.007 \\
\hline $\begin{array}{l}\text { Two-hour glucose } \\
\text { (mg/dL) }\end{array}$ & -2.2 & -3.9 & 0.38 & -2.8 & -7.3 & 0.01 & -5.6 & -10.9 & 0.001 \\
\hline $\begin{array}{l}\text { Glycated hemoglobin } \\
(\%)\end{array}$ & 0.04 & -0.01 & $<0.01$ & -0.03 & -0.09 & $<0.001$ & -0.05 & -0.11 & $<0.001$ \\
\hline Insulinogenic Index & -0.21 & 3.83 & 0.42 & -7.45 & -3.85 & 0.44 & -8.54 & 1.66 & 0.01 \\
\hline $\begin{array}{l}\text { Fasting insulin }(\mu \mathrm{U} / \\
\mathrm{mL})\end{array}$ & 2.76 & 2.61 & 0.83 & -1.44 & -0.93 & 0.43 & 0.64 & -0.19 & 0.16 \\
\hline $\begin{array}{l}\text { Body mass index }(\mathrm{kg} / \\
\left.\mathrm{m}^{2}\right)\end{array}$ & 0.14 & 0.12 & 0.84 & -0.29 & -0.53 & 0.04 & -0.76 & -0.92 & 0.06 \\
\hline
\end{tabular}

Mean changes from baseline are estimated with adjustment for baseline value from mixed models according to use of statin at time of the assessment with $p$ values to indicate difference by statin therapy within treatment groups. Changes after the development of diabetes were excluded in the analyses.

of statistical interaction. Nonetheless, the lower point estimate of the HR in the placebo group could reflect their more rapid progression to diabetes, ${ }^{9}$ providing less opportunity for statin exposure to demonstrably modify the rate of progression to overt diabetes. It is also possible that the somewhat higher HRs in the active treatment groups could reflect a less robust response to the intervention among those with greater baseline diabetes risk, who were also more likely to receive statin therapy (attenuation in model 4).

The earliest report of a statin-diabetes association ${ }^{19}$ suggested a protective effect of pravastatin on diabetes incidence, although diabetes incidence was not determined using standardized criteria. Subsequent statin trials did not confirm this protective effect, and in the Justification of the Use of Statins in Prevention: an Intervention Trial Evaluating Rosuvastatin (JUPITER) statin treatment was associated with an increase in physician-diagnosed diabetes (relative risk: 1.25 ; $95 \%$ CI 1.05 to 1.49 ). In a meta-analysis of six statin trials (including JUPITER), statin use was again associated with increased diabetes risk (OR: 1.13 ; $95 \%$ CI 1.03 to 1.23$).{ }^{20}$ This finding has subsequently been confirmed by others, including a large meta-analysis that included seven additional studies, which together included over 90000 participants, of whom $4.9 \%$ were assigned to statins and $4.5 \%$ were assigned to placebo-developed diabetes (OR: 1.09; 95\% CI 1.02 to 1.17$).{ }^{3}$ Similar HRs for statin-associated diabetes have been reported by other investigators. ${ }^{5621} 22$ In the Women's Health Initiative, ${ }^{21}$ statin use at baseline was associated with increased risk of self-reported diabetes during follow-up (HR 1.71 (1.61 to 1.83)). Further, risk appeared to increase with longer duration of statin therapy. Similar to our analysis, adjustment for possible confounders related to statin use attenuated but did not eliminate the increased risk (adjusted HR 1.48 (1.38 to 1.59$)$ ), indicating that the factors leading to statin use were not themselves sufficient to explain the observed increase in diabetes.

It has been suggested that statins may 'uncover' diabetes in individuals at high risk, which, on a population basis, could result in modest increase in diabetes risk. In a post-hoc analysis of the Treat to New Targets and Incremental Decrease in Clinical Endpoints Through Aggressive Lipid Lowering trials, the effects of statins to magnify diabetes risk were much more strongly evident among those with pre-diabetes than those without pre-diabetes. Similarly, within the JUPITER trial, ${ }^{20} 77 \%$ of those in the intervention arm who developed diabetes during follow-up had impaired fasting glucose at study entry, and further analysis showed that increased statin-associated diabetes risk in this study was limited to participants who had at least one major diabetes risk factor. In an analysis of three other statin trials, fasting glucose, triglycerides, BMI and hypertension emerged as baseline clinical predictors of incident diabetes. ${ }^{23}$ These observations, along with the numerically higher estimates of statin-associated HRs observed in our analyses in DPP participants, suggest that the statin effect is more important among those with pre-existing diabetes risk. Paradoxically, however, variation in baseline diabetes risk factors failed to explain the further risk associated with statin therapy in our cohort, and the HR estimate was greatest among our lifestyle participants, who experienced the largest study-related reductions in diabetes risk.

The mechanisms contributing to effects of statins to modify diabetes risk are poorly understood. A number of studies have assessed changes in insulin sensitivity (mostly using Homeostasis Model Assessement - insulin resistance (HOMA-IR)) during statin treatment. A meta-analysis by Baker et al showed that statins differ in their effect on insulin sensitivity in non-diabetic subjects, with simvastatin decreasing insulin sensitivity, pravastatin increasing sensitivity, and atorvastatin and rosuvastatin showing no 
effect. ${ }^{24}$ In vitro data suggest that some statins may impair insulin signaling and reduce expression of the insulin-responsive glucose transporter, GLUT- $4 .^{25}{ }^{26}$ We saw no evidence of an effect of statins to modify insulin resistance, assessed as fasting insulin concentrations. Statins have been reported to reduce pancreatic beta cell insulin secretion in vitro, but the relevance to insulin secretion in vivo is not known. ${ }^{27} 28 \mathrm{~A}$ recent report in metformintreated subjects with type 2 diabetes demonstrated a reduction in insulin secretion (HOMA- $\beta$ ), no effect of 1 year of treatment with atorvastatin or pravastatin on insulin sensitivity (measured by euglycemic clamp) and modest deterioration in glycemic control (HbA1c). ${ }^{29}$ Our data show evidence for greater deterioration in insulin secretion among statin users, although this was only statistically demonstrated in subjects randomized to the lifestyle arm. This pattern is consistent with previously described metabolic changes underlying progression to diabetes among high-risk individuals ${ }^{30}$ and with our observation that participants in the DPP/DPPOS lifestyle arm who progressed to diabetes had a higher genetic risk score, which largely reflects polymorphisms related to beta cell functioning. ${ }^{31}$ Overall, this suggests an acceleration of typical glycemic deterioration, rather than a unique or statin-specific mechanism.

The strengths of the current analysis include rigorous diabetes ascertainment, prolonged follow-up and updated information about statin use every 6 months. The main limitation of this analysis is that statin treatment was not randomized or protocol-driven, but was based on non-study physician assessments of need for statin treatment based on factors related to CVD risk. The observed association between statin use and diabetes risk in this population was not significantly attenuated after controlling for potential confounders related to indication for statin use. In addition, statin use was based on self-report, which could have resulted in some misclassification. Intensity of statin therapy has been reported to affect diabetes risk, ${ }^{32} 33$ but since statin dose is not available in our cohort, our ability to assess this is limited. For individual patients, a potential modest increase in diabetes risk clearly needs to be balanced against the consistent and highly significant reductions in myocardial infarction, stroke and cardiovascular death associated with statin treatment. Nonetheless, glucose status should be monitored and healthy lifestyle behaviors reinforced in high-risk patients who are prescribed statins for CVD prophylaxis.

\section{Author affiliations}

${ }^{1}$ Department of Medicine and Diabetes Research Center, Albert Einstein College of Medicine, Bronx, New York, USA

${ }^{2}$ Division of Endocrinology and Metabolism, Indiana University School of Medicine, Indianapolis, Indiana, USA

${ }^{3}$ Diabetes Research Institute, University of Miami School of Medicine, Miami, Florida, USA

${ }^{4}$ UCLA Research Center at Alhambra, UC Los Angeles Alhambra, Alhambra, California, USA

${ }^{5}$ Medicine, St Luke's-Roosevelt Hospital, New York, NY, USA
${ }^{6}$ Diabetes and Endocrinology, MedStar Health Research Institute, Hyattsville, Maryland, USA

${ }^{7}$ Department of Family and Preventive Medicine, University of California, San Diego, California, USA

${ }^{8}$ Biostatistics Center and Department of Epidemiology and Biostatistics, Milken Institute School of Public Health, George Washington University, Rockville, Maryland, USA

Acknowledgements The Research Group gratefully acknowledges the commitment and dedication of the participants of the DPP and DPPOS. The sponsor of this study was represented on the Steering Committee and played a part in study design, how the study was done and publication. The funding agency was not represented on the writing group, although all members of the Steering Committee had input into the report's contents. All authors in the writing group had access to all data. The opinions expressed are those of the investigators and do not necessarily reflect the views of the funding agencies. A complete list of centers, investigators and staff can be found in the online supplementary appendix. The funders had no role in study design, data collection and analysis, decision to publish, or preparation of the manuscript.

Contributors JPC, KM, RBG and KW researched the data, edited and reviewed the manuscript, and contributed to discussion. SNR wrote the manuscript and researched the data. SF contributed to discussion. RR and EB-C researched the data and contributed to discussion. MT researched the data, edited and reviewed the manuscript, contributed to discussion, and analyzed the data.

Funding During the DPP and DPPOS, the National Institute of Diabetes and Digestive and Kidney Diseases (NIDDK) of the National Institutes of Health provided funding to the clinical centers and the Coordinating Center for the design and conduct of the study, and collection, management, analysis and interpretation of the data (U01 DK048489). The Southwestern American Indian Centers were supported directly by the NIDDK, including its Intramural Research Program, and the Indian Health Service. The General Clinical Research Center Program, National Center for Research Resources, and the Department of Veterans Affairs supported data collection at many of the clinical centers. Funding was also provided by the National Institute of Child Health and Human Development, the National Institute on Aging, the National Eye Institute, the National Heart Lung and Blood Institute, the Office of Research on Women's Health, the National Institute on Minority Health and Health Disparities, the Centers for Disease Control and Prevention, and the American Diabetes Association. Bristol-Myers Squibb and Parke-Davis provided additional funding and material support during the DPP, Lipha (Merck-Sante) provided medication, and LifeScan donated materials during the DPP and DPPOS. This research was also supported, in part, by the intramural research program of the NIDDK. LifeScan, Health 0 Meter, Hoechst Marion Roussel, Merck-Medco Managed Care, Merck and Co, Nike Sports Marketing, Slim Fast Foods and Quaker Oats donated materials, equipment or medicines for concomitant conditions. McKesson BioServices, Matthews Media Group and the Henry M Jackson Foundation provided support services under subcontract with the Coordinating Center.

\section{Competing interests None declared.}

Ethics approval IRB for George Washington University and the IRBs of each of the participating centers.

Provenance and peer review Not commissioned; externally peer reviewed. Data sharing statement In accordance with the NIH Public Access Policy, we continue to provide all manuscripts to PubMed Central, including this manuscript. DPP/DPPOS has provided the protocols and lifestyle and medication intervention manuals to the public through its public website (https://www.dppos.org). The DPPOS abides by the NIDDK data sharing policy and implementation guidance as required by the NIH/NIDDK (https://www.niddkrepository.org/studies/dppos/).

Author note MT is the guarantor of this work and, as such, had full access to all the data in the study and takes responsibility for the integrity of the data and the accuracy of the data analysis.

Open Access This is an Open Access article distributed in accordance with the Creative Commons Attribution Non Commercial (CC BY-NC 4.0) license, which permits others to distribute, remix, adapt, build upon this work non-commercially, and license their derivative works on different terms, provided the original work is properly cited and the use is non-commercial. See: http://creativecommons.org/licenses/by-nc/4.0/

(c) Article author(s) (or their employer(s) unless otherwise stated in the text of the article) 2017. All rights reserved. No commercial use is permitted unless otherwise expressly granted. 


\section{REFERENCES}

1. Zhou Q, Liao JK. Pleiotropic effects of statins. - Basic research and clinical perspectives -. Circ J 2010;74:818-26.

2. Ridker PM, Danielson E, Fonseca FA, et al. Rosuvastatin to prevent vascular events in men and women with elevated C-reactive protein. N Engl J Med 2008;359:2195-207.

3. Sattar N, Preiss D, Murray HM, et al. Statins and risk of incident diabetes: a collaborative meta-analysis of randomised statin trials. Lancet 2010;375:735-42.

4. Rajpathak SN, Kumbhani DJ, Crandall J, et al. Statin therapy and risk of developing type 2 diabetes: a meta-analysis. Diabetes Care 2009;32:1924-9.

5. Thakker D, Nair S, Pagada A, et al. Statin use and the risk of developing diabetes: a network meta-analysis. Pharmacoepidemiol Drug Saf 2016;25:1131-49.

6. Thakker D, Nair SR, Shukla H, et al. Statin use and risk of developing diabetes in cardiovascular disease: systematic literature review and meta-analysis. Value Health 2014;17:A478.

7. Vallejo-Vaz AJ, Kondapally Seshasai SR, Kurogi K, et al. Effect of pitavastatin on glucose, $\mathrm{HbA} 1 \mathrm{c}$ and incident diabetes: A metaanalysis of randomized controlled clinical trials in individuals without diabetes. Atherosclerosis 2015;241:409-18.

8. Kohli P, Waters DD, Nemr R, et al. Risk of new-onset diabetes and cardiovascular risk reduction from high-dose statin therapy in prediabetics and non-pre-diabetics: an analysis from TNT and IDEAL. $J$ Am Coll Cardiol 2015;65:402-4.

9. Knowler WC, Barrett-Connor E, Fowler SE, et al. Reduction in the incidence of type 2 diabetes with lifestyle intervention or metformin. N Engl J Med 2002;346:393-403.

10. Knowler WC, Fowler SE, Hamman RF, et al. 10-year follow-up of diabetes incidence and weight loss in the diabetes prevention program outcomes study. Lancet 2009;374:1677-86.

11. Report of the expert committee on the diagnosis and classification of diabetes mellitus. Diabetes Care 1997;20:1183-97.

12. Alberti KG, Zimmet PZ. Definition, diagnosis and classification of diabetes mellitus and its complications. Part 1: diagnosis and classification of diabetes mellitus provisional report of a WHO consultation. Diabet Med 1998;15:539-53.

13. Ma Y, Temprosa M, Fowler S, et al. Evaluating the accuracy of an aneroid sphygmomanometer in a clinical trial setting. Am J Hypertens 2009;22:263-6.

14. Diabetes Prevention Program Research Group. The diabetes prevention program: baseline characteristics of the randomized cohort. Diabetes Care 2000;23:1619-29.

15. Ahrén B, Larsson H. Quantification of insulin secretion in relation to insulin sensitivity in nondiabetic postmenopausal women. Diabetes 2002;51(Suppl 1):S202-S211.

16. Brown H, Prescott R, eds. Applied mixed models in medicine. New York: John Wiley \& Sons Inc, 1999

17. Kitabchi AE, Temprosa M, Knowler WC, et al. Role of insulin secretion and sensitivity in the evolution of type 2 diabetes in the diabetes prevention program: effects of lifestyle intervention and metformin. Diabetes 2005:54:2404-14.

18. Hamman RF, Wing RR, Edelstein SL, et al. Effect of weight loss with lifestyle intervention on risk of diabetes. Diabetes Care 2006;29:2102-7.

19. Freeman DJ, Norrie J, Sattar N, et al. Pravastatin and the development of diabetes mellitus: evidence for a protective treatment effect in the West of Scotland Coronary Prevention Study. Circulation 2001;103:357-62.

20. Ridker PM, Pradhan A, MacFadyen JG, et al. Cardiovascular benefits and diabetes risks of statin therapy in primary prevention: an analysis from the JUPITER trial. Lancet 2012;380:565-71.

21. Culver AL, Ockene IS, Balasubramanian R, et al. Statin use and risk of diabetes mellitus in postmenopausal women in the Women's Health Initiative. Arch Intern Med 2012;172:144-52.

22. Mills EJ, Wu P, Chong G, et al. Efficacy and safety of statin treatment for cardiovascular disease: a network meta-analysis of 170,255 patients from 76 randomized trials. QJM 2011;104:109-24.

23. Waters DD, Ho JE, DeMicco DA, et al. Predictors of new-onset diabetes in patients treated with atorvastatin: results from 3 large randomized clinical trials. J Am Coll Cardiol 2011;57:1535-45.

24. Baker WL, Talati R, White CM, et al. Differing effect of statins on insulin sensitivity in non-diabetics: a systematic review and metaanalysis. Diabetes Res Clin Pract 2010;87:98-107.

25. Nakata M, Nagasaka S, Kusaka I, et al. Effects of statins on the adipocyte maturation and expression of glucose transporter 4 (SLC2A4): implications in glycaemic control. Diabetologia 2006;49:1881-92.

26. Chamberlain LH. Inhibition of isoprenoid biosynthesis causes insulin resistance in 3T3-L1 adipocytes. FEBS Lett 2001;507:357-61.

27. Yada T, Nakata M, Shiraishi T, et al. Inhibition by simvastatin, but not pravastatin, of glucose-induced cytosolic $\mathrm{Ca} 2+$ signalling and insulin secretion due to blockade of L-type Ca2+ channels in rat islet betacells. Br J Pharmacol 1999:126:1205-13.

28. Ishikawa M, Okajima F, Inoue N, et al. Distinct effects of pravastatin, atorvastatin, and simvastatin on insulin secretion from a beta-cell line, MIN6 cells. J Atheroscler Thromb 2006;13:329-35.

29. Bellia A, Rizza S, Lombardo MF, et al. Deterioration of glucose homeostasis in type 2 diabetic patients one year after beginning of statins therapy. Atherosclerosis 2012;223:197-203.

30. Weyer C, Bogardus C, Mott DM, et al. The natural history of insulin secretory dysfunction and insulin resistance in the pathogenesis of type 2 diabetes mellitus. J Clin Invest 1999;104:787-94.

31. Hamman RF, Horton E, Barrett-Connor E, et a/Factors affecting the decline in incidence of diabetes in the Diabetes Prevention Program Outcomes Study (DPPOS). Diabetes 2015;64:989-98.

32. Preiss D, Seshasai SR, Welsh P, et al. Risk of incident diabetes with intensive-dose compared with moderate-dose statin therapy: a meta-analysis. JAMA 2011;305:2556-64.

33. Sabatine MS, Wiviott SD, Morrow DA, et al. High-dose atorvastatin asssociated with worse glycemic control: A PROVE-IT TIMI 22 substudy. Circulation 2004;110:S834. 


\section{Correction: Statin use and risk of developing diabetes: results from the Diabetes Prevention Program}

Crandall JP, Mather K, Rajpathak S et al. Statin use and risk of developing diabetes: results from the Diabetes Prevention Program. BMJ Open Diabetes Research and Care 2017;5:e000438. doi:10.1136/bmjdrc-2017-000438.

The Model 5 text in table 2 has been corrected.

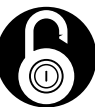

\section{OPEN ACCESS}

Open Access This is an Open Access article distributed in accordance with the Creative Commons Attribution Non Commercial (CC BY-NC 4.0) license, which permits others to distribute, remix, adapt, build upon this work non-commercially, and license their derivative works on different terms, provided the original work is properly cited and the use is non-commercial. See: http://creativecommons.org/licenses/by-nc/4.0/

(C) Article author(s) (or their employer(s) unless otherwise stated in the text of the article) 2017. All rights reserved. No commercial use is permitted unless otherwise expressly granted.

BMJ Open Diab Res Care 2017;5:e000438corr1. doi:10.1136/bmjdrc-2017-000438corr1

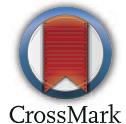

